\title{
A evolução das políticas de desenvolvimento regional no semiárido brasileiro.
}

\author{
Jennifer R. da Silva, Fernando Cézar de Macedo Mota
}

\begin{abstract}
Resumo
O semiárido brasileiro é uma região que tem recebido intervenções públicas desde o final do século XIX, com uma série de políticas regionais voltadas para o combate aos efeitos da seca e promoção de seu desenvolvimento econômico e social. No entanto, essas políticas não parecem ter surtido efeitos em termos de mudanças estruturais, apesar do maior crescimento econômico e melhora dos indicadores sociais a partir dos anos 2000.
\end{abstract}

\section{Palavras-chave:}

Semiárido brasileiro, desenvolvimento regional, políticas regionais.

\section{Introdução}

O semiárido é uma área marcada por grandes e severas secas e é justamente para combater seus efeitos dramáticos que se inicia a intervenção governamental na região, ainda no final do século XIX. Ao longo de todo o século $X X$, foram sendo elaboradas uma série de políticas com vistas a desenvolver a área das secas. Nesse sentido, a criação de órgãos governamentais como o DNOCS, CVSF, CHESF, BNB e, principalmente, a SUDENE foram fundamentais. $O$ trabalho tem como objetivo principal evidenciar a evolução dessas políticas de desenvolvimento regional para o semiárido e identificar se elas contribuíram de fato para o desenvolvimento econômico e social da região.

\section{Resultados e Discussão}

As intervenções do Governo Federal no semiárido brasileiro se iniciaram com a grande seca de 1877-79. É a partir desse momento que as estiagens passam a ser consideradas como um problema nacional. Na primeira metade do século $X X$, as políticas de combate aos efeitos da seca foram marcadas por seu caráter hidráulico. Acreditava-se que os problemas da região eram eminentemente físicos e, portanto, a solução central passava pelos grandes projetos de engenharia através da construção de grandes reservatórios. Neste processo, um órgão governamental foi fundamental, a Inspetoria de Obras Conta as Secas (IFOCS) criada em 1919, que se transformaria no Departamento Nacional de Obras Contra as Secas (DNOCS) em 1945. Além disso, outros elementos fundamentais foram a destinação de fundos para a área das secas através da Constituição de 1934 (4\% da arrecadação), bem como a criação da Comissão do Vale do São Francisco (CVSF) e da Companhia Hidrelétrica do São Francisco (CHESF) em 1948, buscando desenvolver o vale do rio São Francisco.

A partir de 1950 há uma nova abordagem. Entende-se que os problemas da região não eram somente físicos, mas principalmente sociais e, portanto, a solução deveria se dar pelo aumento da renda, do emprego e da produção. De certa forma, a criação do Banco do Nordeste em 1952 está inserida neste contexto, mas o grande marco é a elaboração do documento Uma Política de Desenvolvimento para o Nordeste, dentro do Grupo de Trabalho para o Desenvolvimento do Nordeste (GTDN), que resultou na criação da SUDENE em 1959. A ideia era corrigir as desigualdades regionais e abrir caminho para a industrialização. No semiárido, o objetivo central era uma reestruturação fundiária e modernização da agricultura. No entanto, com o Golpe Militar de 1964, a SUDENE perdeu grande parte de seu poder de decisão. O objetivo central do governo passa a ser a modernização econômica e tecnológica, com a criação de polos de modernização agrícola e pecuária e incentivo à irrigação. Além de programas que visavam fortalecer a agricultura como PIN, PROTERRA e PROVALE. Na década de 1980 o planejamento regional é abandonado em virtude da crise econômica que o Brasil mergulhou. Mas em 1988, com a Constituição Federal, estabelece-se os Fundos Constitucionais de Financiamento, do qual fazia parte o Fundo Constitucional de Financiamento do Nordeste (FNE), que destinava $1,8 \%$ da arrecadação do IPI e IR para a região e destes, $50 \%$ deveriam ser aplicados no semiárido. A ideia dos fundos era diminuir os desequilíbrios regionais.

$\mathrm{Na}$ década de 2000 a política foi orientada pela Política Nacional de Desenvolvimento Regional (PNDR), que buscava pensar a questão regional em múltiplas escalas, levando em conta as especificidades das regiões, sendo o semiárido uma das áreas que a política privilegiaria. No entanto, ela nunca foi de fato implementada. A partir dos anos 2000, observou-se um crescimento mais acentuado da economia do semiárido e de melhora de seus indicadores sociais, principalmente em virtude de investimentos do Estado, incentivos fiscais dos governos estaduais e municipais para atração de empresas e fundamentalmente, as transferências federais que contribuíram para aumentar a renda e o poder de compra da população.

\section{Conclusões}

As políticas de desenvolvimento regional no semiárido brasileiro foram marcadas por práticas inadequadas e um diagnóstico errado acerca dos problemas da região, principalmente até a década de 1950. Na maioria das vezes, as políticas privilegiaram grandes empresas e latifundiários e não o pequeno produtor, contribuindo, inclusive, para um aumento da concentração fundiária. Apesar do crescimento econômico e maior dinamismo a partir dos anos 2000, que se deveu mais a políticas implícitas do que explícitas, o semiárido continua sendo a região com piores indicadores sociais do Brasil, e seus principais problemas estruturais não foram resolvidos, mesmo após as várias políticas regionais instituídas ao longo do século passado.

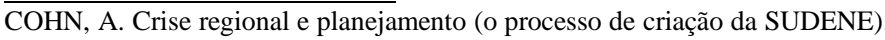
São Paulo: Perspectiva, 1976.

CARVALHO, F.F. Da esperança à crise $\bar{A}$ experiência das políticas regionais no Nordeste. 2001. 164f. Dissertação de Mestrade Universidade Estadual de Campinas, 2001.
} 